\title{
NOVO PROGRAMA, NOVOS ATORES: INOVAÇÃO E AGROECOLOGIA NA AGRICULTURA FAMILIAR DO TOCANTINS
}

\author{
Diego Neves de Sousa ${ }^{1}$ \\ Flávia Charão-Marques ${ }^{2}$ \\ Hellen Christina de Almeida Kato ${ }^{3}$
}

\begin{abstract}
RESUMO
Com o uso da observação participante e da análise documental, este artigo se constitui em um estudo exploratório que propõe compreender como a agroecologia emerge como tema central no debate sobre inovação para a agricultura familiar no estado do Tocantins. Entre os resultados, verificou-se que a partir da criação do Programa Nacional de Inovação e Sustentabilidade na Agricultura Familiar houve maior articulação entre os atores de instituições de ensino, pesquisa e extensão rural na construção de uma rede sociotécnica da Agroecologia. Além disso, foi notável a importância deste processo para fortalecer e promover práticas agroecológicas no Tocantins. Verifica-se, também, que a Agroecologia está intrinsecamente relacionada à emergência de novidades nos espaços rurais, integrando um conjunto aprendizagens, práticas e formas organizacionais.
\end{abstract}

Palavras-chave: concertação, extensão rural, políticas públicas, produção de novidade, sustentabilidade.

\section{NEW PROGRAM, NEW ACTORS: INNOVATION AND AGROECOLOGY IN FAMILY FARMING OF TOCANTINS}

\begin{abstract}
Using participant observation and documentary analysis, this article is an exploratory study that proposes to understand how agroecology emerges as a central topic in the debate on innovation for family farming in the state of Tocantins, North Region of Brazil. Among the results, it was verified that since the creation of the National Program of Innovation and Sustainability in Family Farming there was a better engagement between actors of educational, research and rural extension institution, facilitating the construction of an Agroecology sociotechnical. In addition, the importance of strengthening and promoting agroecological practices in Tocantins was remarkable. We noted that Agroecology is intrinsically related to the emergence

\footnotetext{
${ }^{1}$ Graduado em Gestão de Cooperativas. Mestre em Extensão Rural. Doutorando em Desenvolvimento Rural. Analista da Embrapa Pesca e Aquicultura. E-mail: diego.sousa@embrapa.br

${ }^{2}$ Graduada em Agronomia. Mestre em Fitotecnia. Doutora em Desenvolvimento Rural. Professora da Faculdade de Agronomia (FAGRO) e do Programa de Pós-Graduação em Desenvolvimento Rural (PGDR) da Universidade Federal do Rio Grande do Sul (UFRGS).E-mail: flavia.marques@ufrgs.br

${ }^{3}$ Graduada em Medicina Veterinária. Mestre em Ciência e Tecnologia de Alimentos. Pesquisadora da Embrapa Pesca e Aquicultura. E-mail: hellen.almeida@embrapa.br
} 
of novelties in rural spaces, integrating a set of learnings, practices and organizational forms.

Keywords: concert activity, novelty production, public policy, rural extension, sustainability.

\section{INTRODUÇÃO}

O Programa Nacional de Inovação e Sustentabilidade na Agricultura Familiar foi criado em 2014 com o propósito de integrar ações de extensão rural, pesquisa e ensino, tendo como finalidade central promover a inovação de forma sustentável, por meio de uma rede de atores que atuam junto à agricultura familiar. As atividades do Programa foram propostas pelo Ministério do Desenvolvimento Agrário (MDA) ${ }^{4}$ e passaram a ser executadas em cooperação com a Empresa Brasileira de Pesquisa Agropecuária (Embrapa), no sentido de atender alguns objetivos específicos, a saber: a) promover a construção e compartilhamento de conhecimentos e tecnologias apropriadas na diversidade da agricultura familiar; b) ampliar a oferta e o acesso a tecnologias apropriadas pela agricultura familiar; c) ampliar os espaços de integração entre extensão rural, pesquisa, ensino; e d) ampliar e fortalecer redes de gestão da inovação na agricultura familiar.

De forma a envolver todas as regiões do país, as ações foram sendo estruturadas junto às unidades descentralizadas da Embrapa. Neste âmbito, no estado do Tocantins, a Embrapa Pesca e Aquicultura passou a executar o Programa, seguindo a orientação de buscar respostas para as demandas dos agricultores familiares e de superar desafios na construção de conhecimentos a partir de saberes empíricos e técnico-científicos. Este processo permitiu ampliar o diálogo entre os vários atores sociais partícipes e transformações em relações interinstitucionais, dando visibilidade para uma série de temas relevantes localmente, dentre eles, emergiria a Agroecologia.

Fazendo uso da observação participante e da análise documental, este trabalho se constitui em um estudo exploratório que propõe compreender como a Agroecologia emerge como tema central no debate sobre inovação para a agricultura familiar no estado do Tocantins. Nesta perspectiva, um ponto de partida é que um contexto de transição para a sustentabilidade abrange novos arranjos sociais e técnicos, demandando a construção de redes de aprendizado que favoreçam o estabelecimento de coalizões e negociações, de modo a chegar a novas formas de ação coordenada que potencializem a geração de conhecimento conjunto entre cientistas e agricultores (STUIVER; LEEUWIS; PLOEG, 2004). Desta maneira, é chave para o estudo empreendido a compreensão de que a ampliação de redes sociais, que contribuem para o estabelecimento de nichos inovadores, depende de espaços sociais e institucionais protegidos, uma vez que podem potencializar a emergência de novidades que contribuam com transições no regime dominante da agricultura convencional (CHARÃO-MARQUES, 2009).

$O$ texto a seguir compreende uma seção que esclarece sucintamente a relação entre inovação e a agricultura familiar, apontando para diferentes perspectivas envolvidas, seguida de uma caracterização das ações iniciais

\footnotetext{
${ }^{4}$ Cumpre registrar que o referido ministério foi extinto no ano de 2016, com algumas atribuições repassadas à Secretaria Especial de Agricultura Familiar e do Desenvolvimento Agrário (SEAD) junto à Casa Civil da Presidência da República e para o Ministério do Desenvolvimento Social e Agrário (MDSA).
} 
relacionadas ao Programa de inovação, com isso são analisados os principais aspectos sobre a oficina de concertação, as oficinas temáticas e sua relação com a temática Agroecologia. Na seção seguinte se discute as possibilidades de promoção da inovação na agricultura familiar no Tocantins pautada numa perspectiva de uma nova política e novos atores que atuam com a Agroecologia. Por último, são apresentadas as considerações finais do estudo.

\section{AGRICULTURA FAMILIAR E A INOVAÇÃO TECNOLÓGICA}

Com o reconhecimento da agricultura familiar enquanto categoria social, produtiva e política, principalmente, a partir da implantação do Programa Nacional de Fortalecimento da Agricultura Familiar (PRONAF) em 1995, diversas políticas públicas foram formuladas com o intuito de garantir sua reprodução social e, sobretudo, consolidar seu papel de produtora de alimentos (PICOLOTTO, 2014; ESQUERDO; BERGAMASCO, 2014).

Contudo, esse reconhecimento não deve ser entendido como mera formalidade, mas motivador de novos cenários, como sugere Picollotto (2014): (a) de aumento da importância política do agricultor familiar e dos atores que se constituíram como seus representantes; (b) de reconhecimento institucional propiciado pela definição de espaços no Estado, criação de políticas públicas e da Lei da Agricultura Familiar; e (c) de reversão das valorações negativas que eram atribuídas a esta agricultura (atrasada, ineficiente e inadequada) para o entendimento como uma agricultura que busca ser moderna, eficiente, sustentável, diversificada, solidária e produtora de alimentos.

São várias as decorrências deste reconhecimento da agricultura familiar, destacando-se as políticas de governo e de Estado que visam sanar problemas ligados ao ocultamento de características específicas e a consequente limitação de acesso a recursos diversos ${ }^{5}$. Neste sentido, cabe mencionar a Política Nacional de Assistência Técnica e Extensão Rural (PNATER) ${ }^{6}$ que estabeleceu como público prioritário as diferentes categorias da agricultura familiar, tais como: assentados dos programas de reforma agrária, extrativistas, ribeirinhos, indígenas, quilombolas, pescadores artesanais, aquicultores, povos da floresta, seringueiros entre outros povos tradicionais. De certa forma, este é um marco importante, representando a inserção de atores sociais que historicamente estiveram à margem de políticas públicas.

No entanto, há uma diversidade de posicionamentos e opiniões no que tange à importância ou à forma de participação da agricultura familiar nos processos do desenvolvimento rural. Kageyama, Bergamasco e Oliveira (2013, p. 15) afirmam que a agricultura familiar "é largamente predominante em termos de número de estabelecimentos e de pessoal ocupado, mas com participação proporcionalmente menor no valor da produção e nas receitas do estabelecimento, devido à menor produtividade". Por sua vez, Alves (2001) aponta que as propriedades cultiváveis da agricultura familiar são pequenas não tendo como remunerar melhor a família, sem o aumento da produtividade, pois, "é crucial que a tecnologia seja capaz de aumentar o excedente, de preferência com a redução simultânea de custos. Ou seja, deve fazer cada hectare produzir mais e com menor custo" (ALVES, 2001, p. 15).

Em que pesem as múltiplas variáveis que influenciam diferenciações no setor agrícola brasileiro, e mesmo dentro da ampla categoria 'agricultura familiar', é relevante registrar que a 'tecnologia' parece cumprir um papel proeminente neste

\footnotetext{
${ }^{5}$ Ver Sousa (2014) e Grisa e Schneider (2014).

6 Ver Caporal (2003) e Callou et al. (2008).
} 
processo na opinião de diferentes estudiosos. Merece referência também, a influência que o chamado progresso técnico, baseado nas inovações químicas, mecânicas e biológicas ${ }^{7}$, ainda exerce quando se fala em aumentar a produtividade na agricultura familiar; na medida em que o problema da renda ou ineficiência produtiva aparece como relacionado à questão da 'falta de tecnologia'. "É justamente o progresso técnico a principal arma dos capitalistas menos favorecidos para sobreviverem num mercado em que alguns possuem vantagens redutoras de custos" (GRAZIANO da SILVA, 2003, p. 40, grifo do autor). No mesmo sentido, a substituição de bens caros e escassos por outros abundantes e baratos, tal como preconizado pela Teoria da Inovação Induzida (HAYAMY; RUTTAN, 1988), seria o caminho para ganhar escala de produção. Interessante é perceber que tais noções ainda estão presentes quando pesquisadores são chamados a pensar a inovação, o que parece reeditar princípios que guiaram a modernização agrícola em seus primórdios.

Em suma, o que se verificou num primeiro momento foi que a tecnologia em si foi vista como resposta para o progresso da agricultura, trazendo o incremento de produção e produtividade, o que também é almejado pela agricultura familiar. De certa forma, o progresso técnico enraizou na sociedade a ideia de melhorias na qualidade de vida e mudanças sociais seriam naturalmente decorrentes dos avanços tecnológicos. Contudo, pouco foi questionado sobre o que é 'tecnologia', e a padronização de um conjunto de protocolos técnicos reproduzíveis em diferentes contextos passou a ser entendido tacitamente como tecnologia na agricultura, ainda que a obtenção de produtividades crescentes dependesse do uso de grandes quantidades de energia, insumos externos e capital.

Por outro lado, Trigueiro (2008), afirma que

compreender a complexidade da tecnologia e tratá-la em sua devida singularidade é importante para se formular uma crítica consequente do fenômeno tecnológico recente, evitando-se quaisquer posições ufanistas - como se a tecnologia, sozinha, viesse a resolver todos os problemas da humanidade (a atitude de tratar a tecnologia como uma panaceia) -, bem como toda e qualquer visão essencialmente negativa da tecnologia - como um mal que precisa ser evitado, posto que leva ao aniquilamento da liberdade humana, segundo muitas dessas interpretações (TRIGUEIRO, 2008, p. 135).

Por sua vez, Dagnino e Thomas (2009) também corroboram com tal perspectiva ao explanar que a exclusiva presença de operações atinentes à transferência de tecnologia não é condição suficiente para dar espaço aos processos de inovação. "Os fenômenos de difusão só deveriam ser considerados parte constitutiva da dinâmica de inovação se dão lugar a intervenções - inovações stricto sensu - do receptor sobre a tecnologia recebida; o que, como se sabe, não é a regra" (DAGNINO; THOMAS, 2009, p. 222). Ou seja, a transferência de tecnologia se efetiva ao envolver os agricultores no processo de construção de um conhecimento, factível em sua realidade, abrindo possibilidade de conduzir a inovação de outras maneiras, ou mesmo, questionando o que vem a ser 'inovar'.

Medeiros, Wilkinson e Lima (2002), já no início dos anos 2000, apontavam que os agricultores familiares se apresentam à sociedade como importante vetor para criação em escala local de oportunidades de inclusão produtiva e socioeconômica, ao distinguir um conjunto de qualidades peculiares, muitas vezes,

${ }^{7}$ Ver Graziano da Silva (2003). 
inerentes a seus produtos. Outra informação pertinente dos autores é que os níveis insuficientes de conhecimento costumam retirar das populações tradicionais a possibilidade e a capacidade de agenciar as decisões políticas e comerciais, no que se refere aos seus interesses e demandas, o que também gera marginalização nos aspectos econômico e produtivo.

Inovar na agricultura familiar, então, pode tomar outros rumos. Guivant (1997), ao refletir sobre o conhecimento para uma agricultura sustentável apontava que

trata-se de repensar o papel de agricultores e profissionais agrícolas, tanto na pesquisa quanto na extensão rural, especialmente no sentido de revalorizar as capacidades e as prioridades dos agricultores, envolvendo-os como participantes ativos em todas as fases do desenvolvimento e colocando os conhecimentos locais como elementos-chave na formulação de alternativas produtivas sustentáveis (GUIVANT, 1997, p. 413).

Por fim Costabeber (2006), ao estudar a agricultura familiar de base ecológica, afirma que é a mobilização de uma maior diversidade social que oportuniza a abertura de espaço para um maior protagonismo dos atores sociais locais na busca e geração de alternativas técnicas e organizacionais adequadas às necessidades, capacidades, potencialidades e limitações.

Os aspectos levantados se colocam, em grande medida, em sentido oposto ao padrão estabelecido pelo regime tecnológico ${ }^{8}$ prevalente. Portanto, as mudanças necessárias não estarão em soluções tecnológicas genéricas. Ao contrário, parecem depender muito mais de conhecimentos enraizados localmente; deixando claro que 'localização' não se trata de isolamento e que a inovação, neste caso, não se refere unicamente ao campo da técnica, mas deve articular mudanças na organização social, nos mercados, nos hábitos de consumo, etc. É assim que, a partir da necessidade de particularizar ou evidenciar fenômenos 'inovadores na agricultura', se pode lançar mão do termo-chave 'produção de novidade' (novelty production), proposto para entender mudanças que, muitas vezes, estão 'escondidas' (SWAGEMAKERS, 2003; PLOEG et al., 2004). Uma novidade pode significar uma modificação dentro de uma prática existente ou pode consistir em uma nova prática. Pode, ainda, ser um novo modo de fazer ou pensar, presumivelmente com potencial para promover melhorias nas rotinas existentes (PLOEG et al., 2004).

Novidade, então, é inovação, mas nem toda inovação é uma 'novidade'. Charão-Marques (2011) explica que a inovação e a novidade têm trajetórias distintas, sendo frequentemente bem diferentes em termos substantivos, embora, por vezes, seja impossível distinguir uma da outra. Segundo Oliveira, Gazolla e Schneider (2011), os agricultores familiares, ao romper com as regras e padrões dominantes e optar por outros tipos de produção, acabam por abrir mão da busca de inovações nos mercados ou em instituições de pesquisa e/ou extensão. Assim, os autores explicam que a solução encontrada por eles para minimizar os gargalos vivenciados no cotidiano tem sido criar, resgatar e/ou reconstruir um conjunto de novos procedimentos para produzir, comercializar e processar alimentos.

\footnotetext{
${ }^{8}$ Regime tecnológico pode ser entendido como o conjunto de normas que compreende o complexo do conhecimento científico, práticas de engenharia, processos de produção de tecnologias, características de produtos, habilidades e procedimentos, instituições e infraestruturas que constituem a totalidade da tecnologia (KEMP et al., 1998).
} 
Contudo e apesar da importância que o conhecimento dos
agricultores assume na produção de novidades, foi possível
observar que estes não operam de forma isolada, mas em
diálogo com outros atores sociais, instituições e tipos de
conhecimentos, tais como os conhecimentos dos técnicos que
se relacionavam com os agricultores em busca de novas
alternativas nas iniciativas (OLIVEIRA; GAZOLL;
SCHNEIDER, 2011, p. 45).

Com isto, cabe sublinhar que a gênese da novidade está fundamentalmente ligada à contextualização do conhecimento ${ }^{9}$, envolvendo múltiplos processos de aprendizagens e pressupondo a participação e o envolvimento individual, coletivo e institucional. Medeiros, Wilkinson e Lima (2002), ao chamar atenção para a necessidade de haver investimentos e programas específicos para geração de tecnologia para a agricultura familiar, sugerem que a dimensão tecnológica e os novos conhecimentos capazes de alavancar o desenvolvimento local inovador devem estar apoiados na sustentabilidade e na inclusão social. Mais recentemente, Charão-Marques, Ploeg e Dal Soglio (2012) afirmam que para promover transições para uma agricultura realmente sustentável serão necessárias mudanças de atitudes e novos compromissos sociais de maneira a criar um ambiente de aprendizagem.

Assim, na busca por respostas para as demandas dos agricultores familiares e frente aos desafios para a construção do conhecimento, a partir da comunhão entre o saber empírico e técnico, se constituíram os principais orientadores para a criação do Programa Nacional de Inovação e Sustentabilidade na Agricultura Familiar no âmbito das práticas da extensão rural, pesquisa e ensino, o que será melhor abordado na seguinte seção sobre a experiência deste Programa no Estado do Tocantins.

\section{A CHEGADA DO PROGRAMA NO TOCANTINS}

O Tocantins conta com aproximadamente 43 mil agricultores familiares, que contribuem com $40 \%$ do valor bruto da produção agropecuária e ocupam $50 \%$ das áreas destinadas à agricultura, o que representa $76 \%$ dos estabelecimentos, cujo tamanho médio é 18 ha. ${ }^{10}$ Nos estabelecimentos da agricultura familiar tem-se, em média, 2,7 pessoas ocupadas que possuem algum laço de parentesco com o agricultor, sendo que $84,6 \%$ residem no próprio estabelecimento e $61 \%$ sabem ler e escrever. Deste público, apenas $4 \%$ recebiam salário, 2,3\% trabalhavam somente com atividades não agropecuária e apenas 1,4\% tinham algum tipo de qualificação (IBGE, 2006).

A significativa presença e o respectivo reconhecimento da agricultura familiar no estado não diferem do processo mais geral vivenciado no Brasil desde a década de 1990, ainda que a imagem do estado permaneça bastante relacionada às grandes produções de commodities, em especial, a soja. Em outras palavras, no Tocantins, a importância da agricultura familiar é reconhecida direta e indiretamente, sendo associada a modos de vida pautados por repertórios culturais específicos e a modos de reprodução socioeconômica diversificados.

Sendo assim, é neste contexto que a proposta do Programa Nacional de Inovação e Sustentabilidade na Agricultura Familiar passa a ser debatido, e é

\footnotetext{
${ }^{9} \mathrm{O}$ conhecimento contextual pode ser entendido como resultado da produção social de um fluxo contínuo de acumulação de capacidades e competências tecnológicas (BELUSSI; PILLOTI, 2000).

${ }^{10}$ Fonte: http://seagro.to.gov.br/agricultura-familiar. Acesso em: 23 fev. 2017.
} 
estabelecida uma agenda de ações. Para entender como o processo se inicia é necessário resgatar que a justificativa para o lançamento desta política foi pautada por diversos elementos, tendo nas instituições de extensão rural o principal elo com os públicos da agricultura familiar. As principais explicações para a construção deste Programa são atinentes à demanda por conhecimentos e tecnologias para os extensionistas que atuam nos contratos de ATER estabelecidos pelas chamadas públicas no âmbito da PNATER. Lembrando, também, que os objetivos foram estabelecidos de modo a superar o distanciamento e a desarticulação entre extensão rural, pesquisa e ensino.

Outra definição que o programa estabeleceu é que o público prioritário do programa seriam os agentes de ATER e os agricultores familiares atendidos nas chamadas públicas em andamento. Assim, o trabalho deveria envolver os extensionistas vinculados às instituições, redes de ATER e agricultores com potencial de atuarem como multiplicadores, conhecidos pela sua liderança na comunidade. Metodologicamente, ficaria definido que o primeiro passo seria a realização do que foi chamado de 'Oficina de Concertação', que efetivamente consistiu em reuniões organizadas pela coordenação nacional do Programa em diferentes estados da federação com a participação da Superintendência Federal do MDA (SFDA/TO) e por uma unidade descentralizada da Embrapa. Dentro da mesma lógica, o ponto de partida no Tocantins foi a realização de uma oficina, coordenada pela Embrapa Pesca e Aquicultura e SFDA/TO. As duas entidades, representadas por pesquisadores/analistas e consultores técnicos, respectivamente, estabeleceram articulações institucionais com a finalidade de buscar parcerias junto à sociedade civil e organizações estatais, que atuam com os públicos da agricultura familiar, para levar a cabo os processos de concertação.

\subsection{A OFICINA DE CONCERTAÇÃO}

No Tocantins, foi realizada uma Oficina de Concertação reunindo diversos agentes ligados ao cenário da agricultura familiar, em dezembro de 2014. A finalidade foi identificar os sujeitos e as capacidades de cada ator envolvido com a diversidade da agricultura familiar no estado para definir em conjunto uma agenda de atividades relacionadas as áreas temáticas priorizadas na Oficina de Concertação, além de planejar uma metodologia para operar um grupo gestor, que passaria a ser responsável pela organização das etapas seguintes e mais específicas do Programa.

Foram convidados pela coordenação estadual do Programa, a participar deste evento prospectivo, os diversos segmentos de agricultores familiares e de instituições que poderiam contribuir com o debate sobre inovação para a agricultura familiar. Nesse sentido, foram convidados representantes dos seguintes segmentos: base da agricultura familiar (federação dos trabalhadores, federação e colônia de pescadores, coordenadores dos territórios da cidadania, associações, cooperativas); entidades públicas e privadas de ATER; instituições públicas que atuam direta ou indiretamente no fomento à atividade produtiva; instituições de ensino e pesquisa, tais como: universidades, escolas família agrícola, institutos de ensino, dentre outros. No quadro 1 estão elencadas as 54 instituições participantes, que levaram 130 colaboradores para participar deste primeiro evento. 
Quadro 1 - Instituições participantes da Oficina de Concertação no estado do Tocantins em dezembro de 2014.

\begin{tabular}{|c|c|}
\hline Representantes & Instituições participantes \\
\hline $\begin{array}{l}\text { Agricultura } \\
\text { familiar }\end{array}$ & $\begin{array}{l}\text { Federação dos Trabalhadores na Agricultura do Estado Tocantins (FETAET), } \\
\text { Federação das Associações e Entidades Rurais do Tocantins (FAERTO), Federação } \\
\text { Tocantinense dos Pescadores (FETOPESCA), Conselho Indigenista Missionário } \\
\text { (CIMI) - Regional Goiás/Tocantins, Articulação do Território Jalapão, Articulação do } \\
\text { Território Médio Araguaia, Articulação do Território APA Cantão, Articulação do } \\
\text { Território Bico do Papagaio, Articulação do Território Sudeste, Coordenação Estadual } \\
\text { das Comunidades Quilombolas do Tocantins (COEQTO), Colônia de Pescadores de } \\
\text { Couto Magalhães, Colônia de Pescadores de Araguacema, Cooperativa dos } \\
\text { Pescadores e Artesões de Xambioá (MATRINXAM), Movimento Interestadual das } \\
\text { Quebradeiras de Coco Babaçu (MIQCB), Movimento dos Trabalhadores Sem Terra } \\
\text { (MST). }\end{array}$ \\
\hline $\begin{array}{l}\text { Instituições } \\
\text { públicas }\end{array}$ & $\begin{array}{l}\text { Companhia Nacional de Abastecimento (CONAB), Secretaria de Desenvolvimento da } \\
\text { Agricultura e Pecuária (SEAGRO), Secretaria do Trabalho e da Assistência Social } \\
\text { (SETAS), Secretaria Estadual de Educação (SEDUC), Secretaria de } \\
\text { Desenvolvimento Rural de Palmas (SEDER), Secretaria de Meio Ambiente e } \\
\text { Desenvolvimento Sustentável (SEMADES), Secretaria de Desenvolvimento } \\
\text { Econômico e Emprego (SEDEM/Palmas), Instituto Brasileiro do Meio Ambiente } \\
\text { (IBAMA), Superintendência Federal da Agricultura (SFA/TO), Superintendência } \\
\text { Federal da Pesca e Aquicultura (SFPA/TO), Instituto Natureza do Tocantins } \\
\text { (NATURATINS), Instituto Nacional de Colonização e Reforma Agrária (INCRA), } \\
\text { BANCO DO BRASIL, EMBRAPA. }\end{array}$ \\
\hline $\begin{array}{l}\text { Empresas de } \\
\text { ATER }\end{array}$ & $\begin{array}{l}\text { Instituto de Desenvolvimento Rural do Estado do Tocantins (RURALTINS), Agroter, } \\
\text { Solo Consultoria, Projeto Desenvolve Palmas, Cooperativa } \\
\text { de Trabalho, Prestação de Serviços, Assistência Técnica e Extensão Rural } \\
\text { (COOPTER), Instituto Cerrado e Sociobiodiversidade (ICSBIO), DHES Consultoria, } \\
\text { Cooperativa de Prestação de Serviço Agropecuário (COOPERCAM), Programa } \\
\text { Redes, Consultor da Organização de Estados lbero-americanos (OEI), Serviço } \\
\text { Nacional de Aprendizagem Rural (SENAR), Serviço Nacional de Aprendizagem do } \\
\text { Cooperativismo (SESCOOP). }\end{array}$ \\
\hline $\begin{array}{l}\text { Instituições de } \\
\text { ensino e } \\
\text { pesquisa }\end{array}$ & $\begin{array}{l}\text { Escola Familiar Agrícola (EFA/Porto Nacional), Fundação Universidade do Tocantins } \\
\text { (UNITINS), Universidade Federal do Tocantins (UFT), Instituto Federal do Tocantins } \\
\text { (IFTO), Universidade Luterana do Brasil (ULBRA/Palmas), Faculdade Católica do } \\
\text { Tocantins (FACTO). }\end{array}$ \\
\hline
\end{tabular}

Fonte: Elaborado pelos autores.

A Oficina de Concertação iniciou com a explanação por parte de um moderador sobre os objetivos do evento e uma apresentação sobre o Programa Nacional de Inovação e Sustentabilidade da Agricultura Familiar. Em seguida, foi feita uma contextualização com quatro palestras sobre a agricultura familiar e a inovação tecnológica no Tocantins.

$\mathrm{Na}$ condução da Oficina de Concertação foi utilizada a metodologia "Café do Mundo" "11, que é um método que propicia a criação de uma rede de diálogo colaborativo com rodadas de conversas em grupos em torno de temas relevantes, sistematização e apresentação dos resultados do debate para a plenária (KAMIMURA; PAES; OLIVEIRA, 2012).

A oficina possibilitou levantar problemas e prospectar soluções para a elaboração de uma agenda de ações focada na integração entre ensino, pesquisa e extensão rural no âmbito da agricultura familiar, a fim de viabilizar o planejamento e a execução deste Programa no Tocantins. Os participantes foram divididos em quatro grupos com representantes de todos os segmentos, cada um deles contou

11 O método é baseado nos princípios e no formato desenvolvido pelo The World Cafe (www.theworldcafe.com), um movimento global para apoiar os diálogos relevantes em ambientes corporativos, governamentais e comunitários por todo o mundo. 
com um moderador e um relator, que tiveram a incumbência de sistematizar a discussão, apresentando, em seguida, os desafios e uma proposta de solução para cada problema enunciado. Para cada grupo foi proposto um tema central, quais sejam: sistemas produtivos sustentáveis; organização social e produtiva; agrobiodiversidade e acesso às políticas públicas.

Os grupos tiveram 40 minutos para discutir o tema proposto, em diferentes salas. Ao final de cada rodada era emitido um sinal que indicava que o grupo deveria concluir sua atividade e se dirigir a uma outra sala, para tratar sobre nova temática. Todos os grupos passaram por todas as salas. Houve, ainda, uma quinta rodada, quando os grupos voltaram para a plenária final a fim de consolidarem uma apresentação referente a todas as contribuições concernentes ao tema principal: inovação na agricultura familiar.

Como resultado da oficina, foi estabelecido um calendário de atividades para o ano de 2015, no qual foi incluída a realização de seis oficinas temáticas. Os temas foram definidos em função da necessidade de aprofundamento das discussões identificadas pelos partícipes durante a oficina. Os temas priorizados foram: Agroecologia, Avicultura, Bovinocultura de leite, Mandiocultura, Piscicultura e Pesca. Importante registrar que o grupo decidiu pela realização de uma oficina específica para a Agroecologia. Considerando a Agroecologia como portadora de vários princípios que podem reorientar também as atividades incorporadas nas demais oficinas, o grupo poderia tratá-la de forma transversal, no entanto, a escolha por uma oficina com esse foco parece estar relacionada ao propósito de reforçar a importância da Agroecologia e fortalecer ações específicas neste sentido.

O número de oficinas foi definido de acordo com o recurso financeiro que viria a ser disponibilizado pelo MDA com a finalidade de cobrir o custo de organização de um evento com a capacidade de acolher a participação de, no mínimo, 50 pessoas. Desta forma, entra em cena certo processo de negociação, na medida em que, embora as temáticas tenham sido definidas pela maioria dos atores, a realização efetiva das mesmas dependia também de diferentes interesses institucionais. Por exemplo, o tema Agroecologia foi validado e entendido como prioritário a partir de demandas atinentes a seus subtemas, dentre eles: agrobiodiversidade dos frutos do cerrado, Agroecologia e produção orgânica e a conservação da biodiversidade. Pesou nesta definição o fato de que é aguda e cada vez mais reconhecida a perda da diversidade genética dos cultivos agrícolas locais.

Em outras palavras, a possibilidade aberta pela concertação entre os diferentes atores foi a de aprimorar a discussão no que tange à inovação na agricultura familiar, neste sentido, abriu-se também a possibilidade da execução de uma agenda local, muito embora as prioridades, e mesmo o foco da inovação, ainda tenham permanecido como um debate em construção.

\subsection{AS OFICINAS TEMÁTICAS E SUA RELAÇÃO COM A TEMÁTICA DA AGROECOLOGIA}

Decididas às temáticas, o processo de discussão e organização teve continuidade. Assim, a próxima etapa contou com os eventos nos focos específicos. Seguindo a lógica anterior, os encontros reuniram pesquisadores, agentes de ATER, acadêmicos, técnicos e agricultores. Em especial, foram mobilizados os chamados agricultores experimentadores, que são aqueles identificados como disseminadores de saberes e/ou envolvidos em ações conjuntas de inovação nas localidades.

O objetivo foi identificar, sistematizar e compartilhar conhecimentos e tecnologias para a agricultura familiar, a partir de demandas das unidades familiares, mas também por parte de agentes de ATER. Fundamentalmente, a ideia foi articular 
ações em rede. Note-se que, muito da proposta, vai pelo caminho de potencializar ações e processos em andamento. De alguma maneira, é justamente aí que podemos sublinhar a potencialidade de um programa de inovação que não tenha por base apenas lógica da transferência de tecnologia, na medida em que se favoreça a visibilização de promissoras 'novidades', que podem estar 'escondidas'. O papel primordial destes espaços, como no caso dessas oficinas temáticas, pode ser despertar as novidades, incentivando-as no surgimento de conhecimentos, favorecendo a ampliação de redes nas quais participem os agricultores familiares.

A proposta do formato metodológico das oficinas temáticas previu três momentos. O primeiro momento, foi o de identificar os conhecimentos, a partir de palestras sobre a temática do evento, com apresentações de casos de sucesso mediados por pesquisadores, extensionistas e agricultores experimentadores. $O$ segundo momento foi o de levantar as necessidades e os interesses por meio de discussão sobre a realidade local. Já o terceiro momento foi o de compartilhar os conhecimentos (local e técnico) com o propósito de criar uma agenda de trabalho e a definição do papel de cada ator na construção e execução das atividades propostas.

Ao observar o desdobramento das ações debatidas e propostas nas oficinas é possível perceber que o conjunto dos atores persegue algumas metas no sentido de minimizar deficiências diagnosticadas, bem como articular processos inovativos presentes nas localidades ou nas instituições. Interessante notar que, no contexto dos estudos sobre inovação, normalmente o foco está colocado sobre as novas tecnologias, porém, ao identificar e valorizar a criação de espaços relevantes para as mudanças tecnológicas torna-se possível, também, evidenciar 'velhas' tecnologias que podem estar ali hospedadas, ainda que não estejam estabilizadas no ambiente externo (MARKARD; TRUFFER, 2008). Tais espaços podem ser identificados como 'nichos de inovação',12, nos quais os atores envolvidos têm oportunidade de testar novas tecnologias ou novos arranjos organizacionais que redescubram tecnologias (ou modos de fazer) já existentes, mas que podem ter permanecido descontextualizadas localmente.

Como a proposta do Programa foi abranger todas as regiões do Estado, as seis oficinas foram realizadas no ano de 2015 e em quatro regiões do Tocantins, tendo como organizadoras diversas instituições. Na figura 1, encontram-se localizados os municípios onde foram organizadas as oficinas temáticas e os seus respectivos organizadores.

\footnotetext{
12 Os nichos representam o nível local do processo de inovação. São comumente referidos como espaços protegidos nos quais novas tecnologias e práticas sociotécnicas emergem ou são desenvolvidas. É considerado um espaço privilegiado de onde partem as inovações, inclusive, as radicais (GEELS, 2005).
} 
Figura 1 - Localização onde ocorreram as oficinas e os respectivos organizadores.

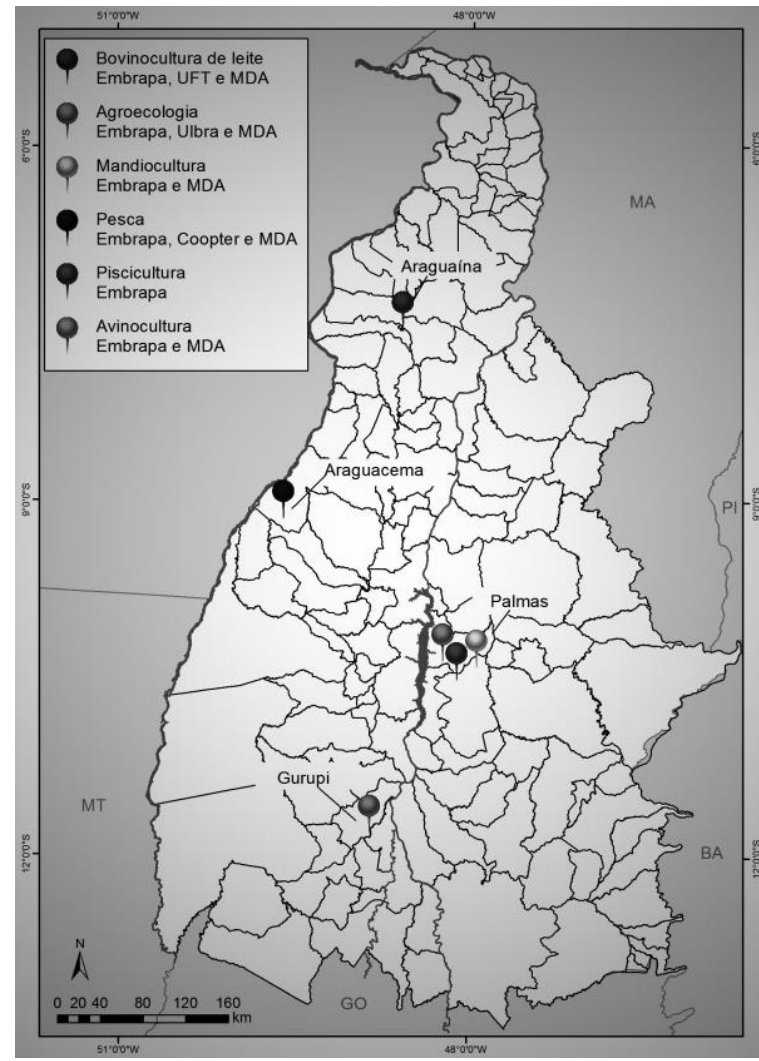

Fonte: Elaborado por Marta Eichemberger Ummus.

A tentativa de descentralização no desenvolvimento das atividades também pode ser um marcador interessante do esforço do Programa em estabelecer um processo diferenciado de facilitação da participação de diferentes atores. Neste sentido, transforma o modo pelo qual, em geral, a inovação é produzida, em um ambiente institucional, muitas vezes, distante dos contextos de aplicação do conhecimento ou tecnologia gerados.

Na lógica de facilitação de 'novidades', é fundamental ter presente que elas surgem em um contexto localizado, sendo aí que elas têm mais chances de resultar em mudanças reais. Por isto, é fundamental que não se restrinjam apenas as questões técnicas, mas que perpassem as questões atinentes aos mercados e ao consumo, assim como, sejam considerados elementos relativos as disputas e embates sociais e políticos nas localidades. Até mesmo porque a contribuição da produção de novidades na agricultura, em processos de transição sociotécnica, pode estar justamente no seu caráter radical, em outras palavras, referindo-se as inovações que frequentemente distanciam, desviam e confrontam as regras e trajetórias dominantes (PLOEG et al., 2004). Neste sentido, "uma novidade interessante que emerge em um lugar (e em um tempo particular), provavelmente, não surgirá em outro ou, se surgir, poderá causar efeitos adversos ou não ser promissora" (CHARÃO-MARQUES, 2011, p. 149). 


\subsection{A OFICINA DE AGROECOLOGIA: PARTICULARIDADES E RESULTADOS}

As oficinas foram organizadas com a proposta de uma carga horária média de 12 horas, perfazendo um dia e meio de atividades, porém, exceção feita à oficina de Agroecologia. Esta foi realizada no período de 13 a 17 de abril de 2015, e diferentemente das demais, por demanda dos atores locais, realizou-se em uma carga horária de 40 horas, divididas entre atividades de discussão ocorridas no Campus Palmas da ULBRA e atividades práticas realizadas durante visitas aos Sistemas Agroflorestais (SAF) instalados na estrutura da ULBRA e no Reassentamento Mariana (Palmas/TO). As instituições envolvidas na oficina de Agroecologia estão apresentadas no Quadro 2. Foram 70 participantes representando a agricultura familiar, instituições públicas, empresas de pesquisa, ensino e ATER.

Quadro 2 - Instituições representadas na oficina temática de agroecologia do estado do Tocantins

\begin{tabular}{|l|l|}
\hline Representantes & \multicolumn{1}{|c|}{ Instituições participantes } \\
\hline Agricultura familiar & $\begin{array}{l}\text { Reassentamento Mariana, Assentamento Santa Clara, Reassentamento Flor da } \\
\text { Serra, Projeto Quitanda do Cerrado - Porto Nacional, Etnia Guajajara - Lagoa } \\
\text { da Confusão, Instituto Mangaba, FAERTO, COEQTO. }\end{array}$ \\
\hline Instituições públicas & $\begin{array}{l}\text { MDA, EMBRAPA, SEDER, SEAGRO, Secretaria de Meio Ambiente e Recursos } \\
\text { Hídricos do Tocantins (SEMARH) INCRA, Fundação Nacional do Índio (FUNAI), } \\
\text { SFA, Ministério Público Federal (MPF). }\end{array}$ \\
\hline Empresas de ATER & RURALTINS, COOPTER. \\
\hline $\begin{array}{l}\text { Instituições de ensino } \\
\text { e pesquisa }\end{array}$ & $\begin{array}{l}\text { ULBRA, Unitas Agroecológica, IFTO, UFT, UNITINS, FACTO, EFA - Porto } \\
\text { Nacional. }\end{array}$ \\
\hline
\end{tabular}

Fonte: Elaborado pelos autores.

O foco do trabalho nos cinco dias de encontro foi a troca de experiências em Agroecologia, tanto as vividas pelos agricultores, quanto pelos atores do mundo do ensino, pesquisa e extensão. Essa troca de experiências permitiu não apenas o intercâmbio de informações, visando demandas em comum e possibilidades de cooperação, como também a visualização de 'novidade' propostas pelo 'outro'. Ou seja, o debate também percorreu possibilidades de adaptação e construção conjunta, seja reunindo saberes locais e conhecimentos técnicos, ou promovendo um repensar de processos para favorecer o surgimento de outras novidades, em outro lugar. Uma vez mais, o Programa parece propor um favorecimento de novas relações, e a inserção de novos atores em processos que levem à inovação. Como mencionado anteriormente, tais encontros e diálogos carregam o potencial de promover transições na medida em que favorecem novos compromissos entre atores e, quiçá, entre as instituições.

Estes aspectos também podem ser percebidos no debate e identificação de desafios e na hierarquização de prioridades. O grupo de atores chegou a quatro eixos que ordenam os desafios para a consolidação e avanço da agroecologia no estado do Tocantins (Quadro 3). Mediante esses desafios, as instituições foram estimuladas a propor ações de maneira individual ou em conjunto, de modo que pudessem ser executadas num calendário factível, com prazos definidos e os respectivos responsáveis a serem contactados pelo comitê gestor para o acompanhamento da solução proposta. 
Quadro 3 - Desafios e ações propostas na oficina temática de Agroecologia do Estado do Tocantins

\begin{tabular}{|c|c|c|}
\hline \multirow[t]{5}{*}{$\begin{array}{l}\text { Compartilhar conhecimentos: } \\
\text { Reconhecer o saber popular, as } \\
\text { práticas de agricultura } \\
\text { sustentáveis, envolver técnicos e } \\
\text { agricultores, considerando as } \\
\text { realidades locais e a } \\
\text { biodiversidade }\end{array}$} & 1. Divulgar casos de sucesso. & $\begin{array}{l}\text { a. Divulgar experiências } \\
\text { com Agroecologia no } \\
\text { estado do TO; } \\
\text { b. Elaborar um site para } \\
\text { divulgação de materiais e } \\
\text { atividades. }\end{array}$ \\
\hline & $\begin{array}{l}\text { 2. Capacitar os agentes de } \\
\text { ATER (Priorizar as chamadas } \\
\text { vigentes) para trabalhar com } \\
\text { Agroecologia e saberes } \\
\text { tradicionais. }\end{array}$ & $\begin{array}{l}\text { a. Formar um grupo de } \\
\text { trabalho para elaborar um } \\
\text { projeto de capacitação } \\
\text { específico. }\end{array}$ \\
\hline & $\begin{array}{l}\text { 3. Identificar espaços de } \\
\text { referências. }\end{array}$ & $\begin{array}{l}\text { a. Mapear as experiências } \\
\text { agroecológicas/SAF's } \\
\text { existentes no TO. }\end{array}$ \\
\hline & $\begin{array}{l}\text { 4. Desenvolver pesquisas em } \\
\text { Agroecologia/SAF's, como } \\
\text { validação de tecnologias para o } \\
\text { TO, estudos de viabilidade } \\
\text { econômica. }\end{array}$ & $\begin{array}{l}\text { a. Levantar as pesquisas e } \\
\text { relatos de experiências } \\
\text { existentes nas } \\
\text { universidades e institutos de } \\
\text { ensino; } \\
\text { b. Organizar um seminário } \\
\text { anual para apresentação } \\
\text { das pesquisas com } \\
\text { Agroecologia; } \\
\text { c. Elaborar projeto de } \\
\text { pesquisa para o estudo de } \\
\text { viabilidade econômica das } \\
\text { atividades existentes. }\end{array}$ \\
\hline & $\begin{array}{l}\text { 5. Criação de uma rede de trocas } \\
\text { de sementes. }\end{array}$ & $\begin{array}{l}\text { a. Identificar materiais } \\
\text { crioulos do estado; } \\
\text { b. Estimular a multiplicação } \\
\text { dos materiais nativos, via } \\
\text { PAA Sementes. }\end{array}$ \\
\hline $\begin{array}{l}\text { Elaborar o Plano Estadual de } \\
\text { Agroecologia }\end{array}$ & $\begin{array}{l}\text { 1. Participar da elaboração do } \\
\text { Plano Regional de Agroecologia. }\end{array}$ & $\begin{array}{l}\text { a. Discutir a aplicação do } \\
\text { Plano Nacional de } \\
\text { Agroecologia e Produção } \\
\text { Orgânica (PLANAPO) no } \\
\text { Tocantins. }\end{array}$ \\
\hline \multirow[t]{2}{*}{$\begin{array}{l}\text { Organização da Rede de } \\
\text { Agroecologia }\end{array}$} & 1. Manter o contato do grupo; & $\begin{array}{l}\text { a. Criar canais de } \\
\text { comunicação (hotsite, } \\
\text { mailing, redes de contatos, } \\
\text { redes sociais, etc.) }\end{array}$ \\
\hline & $\begin{array}{l}\text { 2. Promover um encontro da } \\
\text { Rede de Agroecologia do TO. }\end{array}$ & $\begin{array}{l}\text { a. Realizar reunião para } \\
\text { articular a formação e } \\
\text { funcionamento da rede: } \\
\text { Atores, atribuições, } \\
\text { atividades, etc. }\end{array}$ \\
\hline $\begin{array}{l}\text { Facilitar o processo de emissão } \\
\text { de DAP's indígenas }\end{array}$ & $\begin{array}{l}\text { 1. Promover um encontro entre } \\
\text { FUNAI, MDA, Ruraltins, } \\
\text { FETAET, COOPTER, MPF, } \\
\text { Banco da Amazônia e Banco do } \\
\text { Brasil. }\end{array}$ & $\begin{array}{l}\text { a. Enviar convites e mandar } \\
\text { programação para os } \\
\text { envolvidos. Resgatar casos } \\
\text { de sucesso para } \\
\text { compartilhamento. }\end{array}$ \\
\hline
\end{tabular}

Evidencia-se que esta agenda local, construída com base nas demandas e oportunidades levantadas durante a oficina, é fruto de um processo de diálogo horizontal entre os diversos atores, tendo havido um protagonismo relevante dos agricultores familiares em indicar para as instituições de pesquisa, ensino e de extensão suas demandas. Também, a Agroecologia, como um heterogêneo projeto 
orientador da construção de uma agricultura e um rural sustentável. Deste modo, vão se desenhando múltiplas vias para sua ampliação no estado, todavia, na medida em que se contrapõe à agricultura convencional, não conta com suportes e instrumentos institucionais consolidados. Neste sentido, os agricultores que começar a orientarem-se pelos princípios agroecológicos em seus processos produtivos se apresentam como grandes demandantes de conhecimento e inovação. Ao analisar o conjunto das propostas, fica evidente que elas congregam, em geral, ações que envolvem compartilhamento de conhecimentos e/ou aprofundamento de relações, esta última, talvez, se constitua justamente em outra faceta da demanda, a facilitação de laços e compromissos entre os atores.

Dessa forma os agricultores familiares envolvidos com a Agroecologia, no Tocantins, parecem reclamar mais fortemente espaços e condições para uma construção conjunta do processo de inovação, considerando muito do desenvolvimento de soluções técnicas e tecnológicas que têm sido construídas pela própria comunidade. Em outras palavras, parecem buscar meios de promover uma sintonia entre conhecimentos locais e o conhecimento técnico-científico, ao invés de demandar soluções prontas e tecnologias acabadas. Ainda que a demanda por soluções tecnológicas específicas, como variedades mais produtivas ou capacitação continuada para obter melhores rendimentos na unidade familiar, não desapareça da pauta.

A transição para modelos agroecológicos de produção tem sido bastante demandada pelos agricultores familiares às empresas de ATER e de pesquisa no estado. Com este propósito, no ano de 2015, o Tocantins foi contemplado com um contrato de ATER do MDA, no entanto, dentre os extensionistas que atuaram nesta atividade eram poucos os que tinham conhecimento e experiência em intervenções nesta área do conhecimento. Por isso que houve uma priorização na oficina em capacitar os agentes de ATER para trabalhar com Agroecologia e saberes tradicionais.

No entanto, a discussão sobre o que é inovação e a caracterização dos desafios enfrentados pelos agricultores no campo da Agroecologia perpassou um debate mais instrumental sobre transferência de tecnologia, do que propriamente a noção de novidade e a contextualização do conhecimento. Assim, apesar de ter sido enfatizada a necessidade de compartilhar conhecimentos e do crescente reconhecimento do saber popular, ainda há barreiras a superar para envolver mútua e reciprocamente técnicos e agricultores, bem como ampliar redes de ATER que possam integrar fluxos de aprendizagem coletiva, catalisar processos, ao invés de cumprir o velho papel de fazer uma 'ponte' entre pesquisa e o agricultor.

Quanto à avaliação do evento, os participantes avaliaram de ótima forma, tomados aspectos relativos ao conteúdo e carga horária, com as médias oscilando entre 8,00 a 8,83 e com desvios padrão relativamente baixos (Ver Figura 2). 
Figura 2 - Média e desvio padrão relativos à avaliação da Oficina Temática da Agroecologia do estado do Tocantins

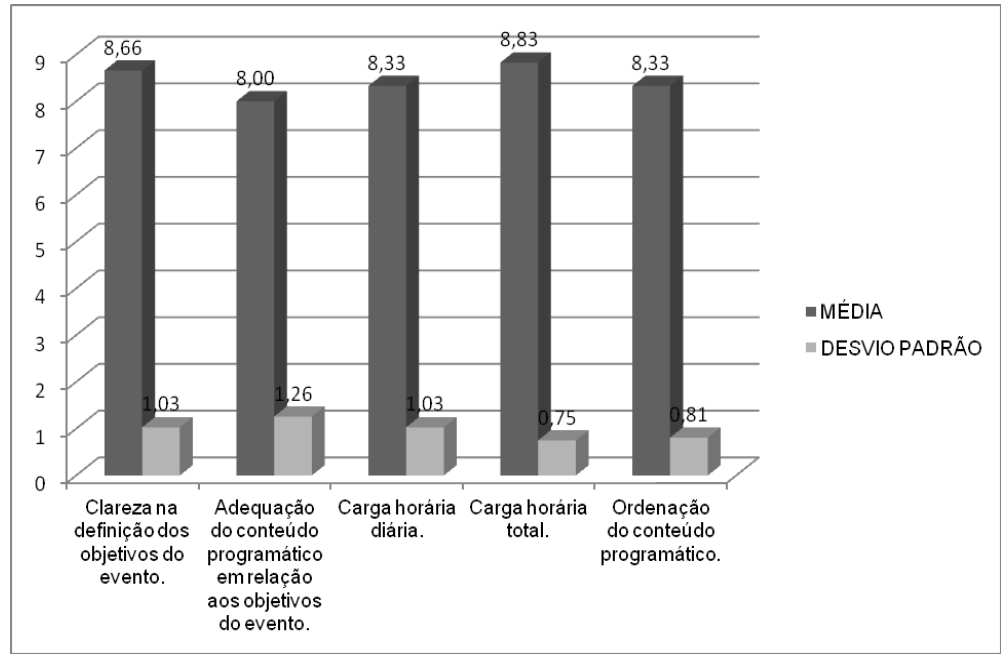

Fonte: Elaborado pelos autores.

Os aspectos relativos ao envolvimento dos participantes foram ainda melhor avaliados (Figura 3), considerando que as médias calculadas foram bastante altas. De modo geral, pode-se inferir que os participantes perceberam positivamente 0 grau de engajamento das representações institucionais com a temática e o empenho de todos os atores envolvidos na proposição da agenda final.

Figura 3 - Média e desvio padrão relativos à avaliação dos participantes da Oficina Temática da Agroecologia do estado do Tocantins

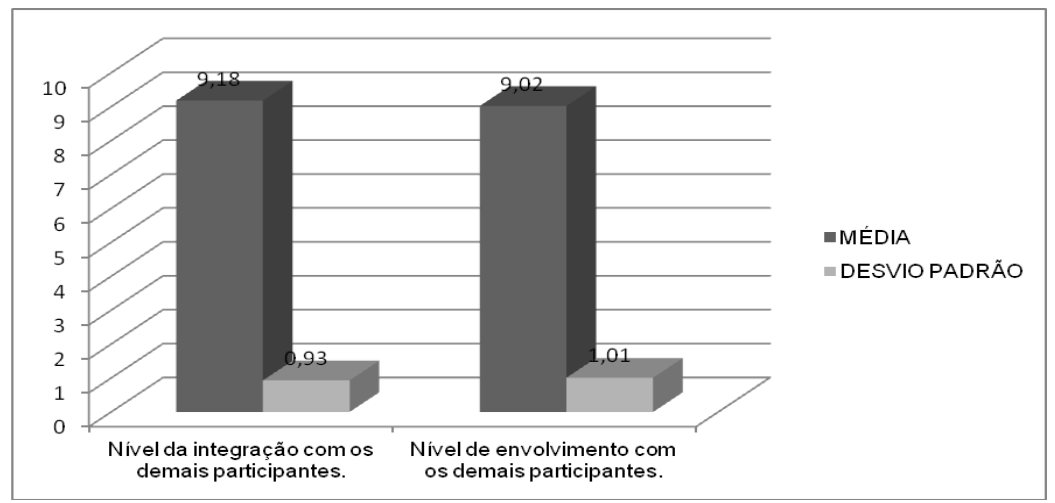

Fonte: Elaborado pelos autores.

A avaliação realizada com os participantes mostrou que o Programa favoreceu o estabelecimento de um diálogo mais horizontal em diversas instâncias representativas e com inserção de novos atores. 'Novos' no sentido de que os agricultores familiares (e os saberes locais) estiveram à margem dos processos de 
inovação ou foram aqueles que, em grande medida, passaram a 'consumir' as chamadas tecnologias que foram desenvolvidas sem considerar suas especificidades. Deste modo, também parece emergir de tal diálogo os elementos práticos necessários para promover a inovação no contexto da realidade dos agricultores familiares.

Possivelmente, este é o caso de avanços observados com os processos de concertação, uma vez que reuniu diversas instituições que frequentemente realizavam ações em comum, mas que não se interagiam uma com a outra. Com isso, o grupo de atores participantes do Programa parece ter melhorado sua atuação no que tange à organização das ações em torno da construção do conhecimento agroecológico, como foi o caso de um maior estreitamento nas relações entre as instituições que compõem a Comissão da Produção Orgânica do Estado do Tocantins (CPOrg-TO), a organização de uma rede sociotécnica de Agroecologia e a iniciativa de elaborar o Plano Estadual de Agroecologia aos moldes do PLANAPO.

Contudo, com a extinção do MDA em 2016, não houve mais ações relativas ao Programa, paralisando atividades que necessitavam de recursos financeiros. Dessa forma, o Programa não pode mais prosperar como uma política pública propriamente dita, pois as ações vão depender cada vez mais das articulações locais para o que foi proposto na agenda de trabalho seja colocado em prática. Ainda assim, algumas ações estão em andamento de acordo com o planejamento da agenda realizada na oficina, em especial, aqueles que fazem parte de acordos de cooperação técnica formalizados entre as instituições que atuam com a temática da Agroecologia no Tocantins.

\section{CONSIDERAÇÕES FINAIS}

A breve reflexão proposta neste artigo mostra que, com o Programa Nacional de Inovação e Sustentabilidade na Agricultura Familiar no Tocantins, foi possível problematizar e resgatar a discussão sobre a inovação no estado. Uma das primeiras constatações da análise empreendida é que havia um real distanciamento entre os múltiplos atores ligados à agricultura familiar e, em especial, relacionados à produção de conhecimentos e inovação.

Também, pode-se destacar que a proposta e a escolha metodológica no âmbito do Programa favoreceram o protagonismo dos agricultores, ultrapassando a noção de que eles são receptores passivos de tecnologias e de políticas públicas, e apontando que, como atores sociais significantes, podem ser partícipes na definição de estratégias e busca de soluções em conjunto com técnicos e pesquisadores (e suas respectivas instituições).

As oficinas possibilitaram a construção de uma agenda de trabalho com a articulação de esforços e competências, criando um ambiente de integração e compartilhamento de expectativas, o que pode corroborar com a formação de nichos de inovação. Este potencial parece ter surgido do diferencial metodológico das oficinas, na medida em que a agenda de discussão e posteriormente de ações foram pautadas pelo encontro do conhecimento local e do técnico-científico.

Os desafios diagnosticados para a geração da inovação tecnológica abrangem questões atinentes aos sistemas produtivos, à organização social e produtiva, à agrobiodiversidade e ao acesso a políticas públicas. Neste sentido, tais elementos serão fundamentais na construção de uma agenda de inovação para o estado do Tocantins de modo a atender a agricultura familiar, ainda que dentro de cenários de indefinições políticas e descontinuidades de ações previamente acordadas. De fato, o Programa conseguiu aproximar atores que anteriormente pouco se conheciam e tampouco interagiam, nestes encontros reside o potencial de 
continuidade das transformações, considerando que laços foram estabelecidos e expectativas tendem a ser compartilhadas entre os participantes do processo, para além da ação unicamente direcionadas pelo Programa especificamente.

Verificou-se, então, que a partir da ampliação de redes de atores no estado houve maior contribuição para o estabelecimento de nichos que podem dar abrigo à inovações, ou seja, emergiram espaços sociais e institucionais capazes de 'proteger' inovações ainda não completamente consolidadas. Todavia, permanecem os desafios de ampliar a compreensão sobre as diferentes formas de inovação. Em especial, no sentido de fortalecer e promover a construção do conhecimento agroecológico no Tocantins, uma vez que ele está intrinsecamente relacionado à emergência de novidades no meio rural, integrando um conjunto de processos, práticas e formas organizacionais entre os diferentes atores sociais. Destaca-se, ainda, que, apesar da vitalidade das redes emergentes, das parcerias e compromissos estabelecidos entre atores e instituições atuantes localmente, a descontinuidade do Programa e de outras políticas públicas ameaçam avanços considerados fundamentais para a transição em direção à sustentabilidade da agricultura na região e no país.

Mesmo com essa situação, as ações corroboraram substancialmente para a emergência do debate e das práticas agroecológicas entre os diversos atores que atuam direta e indiretamente com a Agroecologia nas distintas regiões do Tocantins, o que pode estar propiciando maior capilaridade de instituições que estão envolvidas em rede.

\section{REFERÊNCIAS}

ALVES, E. Agricultura familiar prioridade da Embrapa. Brasília: Embrapa Informação Tecnológica, 2001.

BELUSSI, F.; PILOTTI, L. Knowledge creation and collective learning in the Italian local production systems. Dipartamento de Scienze Economiche Marco Fanno, Università degli Studi di Padova, 2000.

CALlOU, A. B. F.; PIRES, M. L. L. S.; LEITÃO, M. R. F. A.; SANTOS, M. S. T. O estado da arte do ensino da extensão rural no Brasil. Extensão Rural, Santa Maria. Ano XV, n. 16, jul./dez. 2008. Disponível em: <http://w3.ufsm.br/extensaorural/art4ed16.pdf >. Acesso em: 15 set. 2017.

CAPORAL, F. R. Bases para uma nova ater pública. Extensão Rural, Santa Maria, n. 10, 2003. Disponível em: <https://periodicos.ufsm.br/extensaorural/article/view/5546/3271>. Acesso em: 16 set. 2017.

CHARÃO-MARQUES, F. Velhos conhecimentos, novos desenvolvimentos: transições no regime sociotécnico da agricultura. A produção de novidades entre agricultores produtores de plantas medicinais no Sul do Brasil. 220 f. 2009. Tese (Doutorado em Desenvolvimento Rural) - Faculdade de Ciências Econômicas, Universidade Federal do Rio Grande do Sul.

CHARÃO-MARQUES, F. Nicho e novidade: nuanças de uma possível radicalização inovadora na agricultura. In: SCHNEIDER, S; GAZOLLA, M. (Orgs.). Os atores de desenvolvimento rural: práticas produtivas e processos sociais emergentes. Porto Alegre: Editora da UFRGS, 2011. p. 145-158. 
CHARÃO-MARQUES, F.; PLOEG, J. D.; SOGLIO, F. K. New Identities, new commitments: something is lacking between niche and regime. In: ELZEN, B; BARBIER, M. (Org.). System innovations, knoledge regimes, and design practices towards sustainable agriculture. $1^{\text {a }}$ ed. Tolouse, 2012, p. 23-46.

COSTABEBER, J. A. Transição agroecológica: rumo à sustentabilidade. Revista Agriculturas, v. 22, p. 4-5, 2006.

DAGNINO, R.; THOMAS, H. Planejamento e políticas públicas de inovação: em direção a um marco de referência latino-americano. Planejamento e Políticas Públicas (23). Brasília: IPEA, 2001.

ESQUERDO, V. F. S.; BERGAMASCO, S. M. P. P. Análise sobre o acesso aos programas de políticas públicas da agricultura familiar nos municípios do circuito das frutas (SP). Revista de Economia e Sociologia Rural, v. 52, p. 205-222, 2014.

GEELS, F. W. The dynamics of transitions in socio-technical systems: a multi-level analysis of the transition pathway from horse-drawn carriages to automobiles (18691930). Technology Analysis \& Strategic Management, London, v. 17, n. 4, p. 445476, 2005

GRAZIANO da SILVA, J. O Progresso Técnico na Agricultura. In: GRAZIANO da SILVA, J. Tecnologia \& Agricultura Familiar. 2 ed. Porto Alegre: Editora da UFRGS, 2003, p. 13-50.

GRISA, C.; SCHNEIDER, S. Três gerações de políticas públicas para a agricultura familiar e formas de interação entre sociedade e Estado no Brasil. Revista de Economia e Sociologia Rural, v. 52, p. 125-146, 2014.

GUIVANT, J. Heterogeneidade de conhecimentos no desenvolvimento rural sustentável. Cadernos de Ciência e Tecnologia, v. 14, n. 3, p. 411-446,1997.

HAYAMI, Y.; RUTTAN, V. Desenvolvimento agrícola: teoria e experiências internacionais. Brasília: Embrapa, 1988.

IBGE - Instituto Brasileiro de Geografia e Estatística. Censo Agropecuário, 2006.

KAgeyAmA, A. A.; BeRgamasco, S. M. P. P.; OLIVEIRA, J. T. A. Uma tipologia dos estabelecimentos agropecuários do Brasil a partir do censo de 2006. Revista de Economia e Sociologia Rural, v. 51, n. 1, p. 105-122, 2013.

KAMIMURA, Q. P.; PAES, E. S.; OLIVEIRA, E. A. A. Q. Inovação tecnológica: início de novos negócios em TI - estudo de caso numa empresa de bens de capital do Vale do Paraíba. Latin American Journal of Business Management, v. 3, n. 2, p.174-187, 2012.

KEMP, R.; SCHOT, J.; HOOGMA, R. Regime shifts to sustainability through processes of niche formation: the approach of Strategic Niche Management. Technology Analysis \& Strategic Management, v. 10, n. 2, p. 175-196, 1998. 
MARKARD, J.; TRUFFER, B. Technological innovation systems and the multi-level perspective: towards an integrated framework. Research Policy, Amsterdam, n. 37, p. 596-615, 2008.

MEDEIROS, J. X.; WILKINSON, J.; LIMA, D. M. A. O desenvolvimento científico e tecnológico e a agricultura familiar. In: LIMA, D. M; WILKINSON, J. (Orgs.). Inovação nas tradições da agricultura familiar. Brasília: CNPq/Paralelo 15, 2002. p. 23-38.

OLIVEIRA, D.; GAZZOLA, M.; SCHNEIDER, S. Produzindo novidades na agricultura familiar: agregação de valor e agroecologia para o desenvolvimento rural. Cadernos de Ciência \& Tecnologia, v. 28, n. 1, p. 17-49, 2011.

PICOLOTTO, E. L. Os atores da construção da categoria agricultura familiar no Brasil. Revista de Economia e Sociologia Rural, v. 52, p. 63-84, 2014.

PLOEG, J. D. et al. On Regimes, novelties, niches and co-production. In: WISKERKE, J. S. C.; PLOEG, J. D. van der. Seeds of Transition. Assen: Royal van Gorcum, 2004. p. 1-30.

SOUSA, D. N. Os estudos de extensão pesqueira nos programas de pós-graduação em extensão rural. Extensão Rural, Santa Maria, v. 21, n. 4, p. 32-51, 2014. Disponível em: <https://periodicos.ufsm.br/extensaorural/article/view/9092/pdf> Acesso em: 15 set. 2017.

STUIVER, M.; LEEUVIS, C.; PLOEG, J. D. The power of experience: farmer's knowledge and sustainable innovations in agriculture. In: PLOEG, J. D. van der; WISKERKE, J. S. C. Seeds of transition. Assen: Van Gorcumm, 2004, p. 93-118.

SWAGEMAKERS, P. Novelty production: new directions for the activities and role farming. In: HUYLENBROECK, G. van; DURAND, G. Multifunctional agriculture: a new paradigm for european agriculture and rural development. Hampshire: Ashgate, 2003. p. 189-207.

TRIGUEIRO, M. G. S. O conteúdo social da tecnologia. Brasília: Embrapa Informação Tecnológica, 2008. 